\title{
Semantic Peculiarities of Feminine Derivatives in the Old English Language
}

\author{
N. Yesypenko, O. Soloviova
}

\author{
Chernivtsi National University named afer Yurii Fedkovych
}

Paper received 04.04.20; Accepted for publication 20.04.20.

\section{https://doi.org/10.31174/SEND-Ph2020-226VIII68-15}

\begin{abstract}
The article deals with the relationship between semantics and suffixes in Old English. It has been hypothesized that suffixes that form nouns belonging to a particular gender have certain segments of meaning that differ from those of other genders during the same period of language evolution. In order to identify such features, an analysis of feminine derivatives was conducted. The analysis of semantic segments was based on identifying twenty-one semantic segments, inherent in derivatives and their bases. Our findings show that the main semantic segments characteristic of feminine suffixes include abstractions, feelings and traits of character, names of actions and results of actions.
\end{abstract}

Keywords: Old English, semantic motivation, gender, suffixes, non-recursive derivation, semantic groups.

\begin{abstract}
The question we are investigating within this article is the continuation of the statement offered by I. Mel'c uk who states that 'We say that agreement classes of the noun in language are genders if and only if the following eight conditions are simultaneously satisfied to a sufficient degree: ... They manifest a direct link with the biological sex of the being denoted by the noun: a noun referring to a male belongs to one class and that referring to a female to another class... Beside the sexual division, these classes do not show a sufficiently visible semantic motivation: in most cases, there is no direct link between the meaning of a noun and its gender' [4, p. 325]. But later in the same research he makes an assumption that the absence of semantic motivation for gender is not absolute. As a derivational suffix often imposes a particular gender on a derived noun and in this way establishes a correlation between meaning and gender. Even among non-derived nouns, a number of semantically related nouns can end up regrouped in the same gender under the influence of semantic analogy. Though this phenomenon is rather exceptional for gender; it is limited and disparate. To discover semantic motivation of gender for a group of nouns requires special research [4]. As Modern English has no grammatical gender it is obviously significant to explore and establish the possibility of certain gender to have a visible semantic motivation in the past and trace its influence on further periods of language evolution.
\end{abstract}

The material of the article includes 1096 nouns formed by means of suffixation (8 suffixes) in the Old English period from An Anglo-Saxon Dictionary [1]. In the analysis we focus on the suffixes and the characteristics of the bases of derivation. We believe that bases of derivation as well as derivatives can show tendencies that can explain or help us understand the further development of coined words semantic content. We have chosen feminine gender derivatives as it allows the greatest number of derivational patterns in the material under study, thus the results of investigation prove to be valid and reliable. In order to avoid possible ambiguity we analysed only non-recursive derivatives, that is we restricted our analysis to only 'one stem plus one suffix' derivatives.

To carry the analysis we have set 21 semantic groups to identify the meaning of derivatives and bases and define this process as creating a meta-language for our investigation. Some of the groups seem to be close in meaning, for example "activity"-“state"-"result". A. Zbierska-Sawala in her work noted that the categories of action and state are intrinsically related, and in certain contexts deverbal nouns can be seen as expressing states which result from action. A result noun might then express a mental or physical state (repentance, absence, or simply a state of affairs, deficiency) [7, p. 20]. But we adhere to our meta-language with the purpose of finding possible semantic peculiarities.

The following 21 groups would be discussed in this article:

Group 1 Notions of Humans

Group 2 Social Stratification

Group 3 Family

Group 4 Administration

Group 5 Traits of Character

Group 6 Feelings

Group 7 Skills/knowledge

Group 8 Age

Group 9 Abstractions

Group 10 Social Activities

Group 11 Physical Activities

Group 12 Physiological Activities

Group 13 Result of Actions

Group 14 State

Group 15 Religion

Group 16 War

Group 17 Animals

Group 18 Lifeless Objects

Group 19 Food/Taste

Group 20 Structures

Group 21 Locations

As the next step of our research we conducted an analysis of all feminine suffixes on the basis of their derivatives semantic characteristics. Its aim was to establish semantic peculiarities of each suffix separately.

In the Old English period suffix -ung was one of the most productive suffixes used to form nouns (feminine gender) from verbs (200 verbal bases were fixed), substantival bases (110 derivatives in Old English), adjectives (34 cases) and other parts of speech (adverbs, prepositions etc.). As a result the most frequent semantic component of bases is activity.

The main meaning that the suffix -ung possesses in the Old English period is denoting process:

Physical Activities - 72 nouns;

e.g. N,f creóp - ung - Ø 


\section{$\mathrm{V}$, s2 creópan -process - FEM.NOM.SG \\ Social Activities - 62 nouns; \\ e.g. N, f hǽlett -ung - Ø \\ $\mathrm{V}$, w1 hálettan -process- FEM.NOM.SG}

The next component of meaning characteristic of the suffix -ung is Feelings ( $G r l)$, which we define as state. These nouns are formed from nouns, adjectives and verbs that mostly belong to feelings, abstract notions and actions.

$$
\text { Feelings - } 62 \text { nouns; }
$$

e.g. N,f prút - ung - Ø

Adj. prút - being FEM.NOM.SG

One more semantic meaning of the suffix -ung is result.

Result - 62 nouns;

e.g. N,f ǽwn - ung - Ø

V, w2 ǽwnian - result FEM.NOM.SG

The last semantic group that has considerable representation is abstraction. 21 nouns with suffix -ung belong to this group.

Abstraction - 21 nouns;

e.g. N,f wundr

$\mathrm{N}, \mathrm{n}$ wundor

-ung

FEM.NOM.SG

The suffix -ness was used to form abstract nouns from adjectives (186 case), nouns ( 76 cases), verbs (64 cases) and other parts of speech (12 cases).

The most numerous semantic group of nouns coined by -ness is abstraction.

Abstraction - 50 nouns;

e.g. N,f swǽr -ness- $\varnothing$

Adj. wundor - abstraction FEM.NOM.SG.

The next group is result, which is represented by nouns coined from social and physical activities.

Result - 43 nouns;

e.g. N,f breót -ness- $\varnothing$

V, s2 breótan - result FEM.NOM.SG.

The next segment of meaning characteristic of the suffix -ness combines two groups: Feelings and Traits of Character. All together they account for 67 derived words.

Feelings and character segments are indicative for the overall semantics of the suffix, as first of all show the anthropocentric character of the suffix, at the same time opposing -ness to -ung in terms of their meaning specialization.

The next one is state. This group is represented by nouns coined from activities, adjectives, and heterogeneous words.

State - 46 nouns;

e.g. N,f beald -ness $-\varnothing$

Adj. beald - character FEM.NOM.SG.

OE -leást is unique as it belongs to the privative semantic category, which is not frequent among noun suffixes. The dictionary defines it as "suffix forming nouns denoting lack, want or absence of"; and it should be stated that this suffix is not preserved in the Modern English period.

The OE suffix works mostly with nouns of all three genders (feminine nouns -8 cases, masculine and neuter - 9 cases each). Nouns mostly belong to Abstraction (9 cases) and Character (4 cases). Other semantic groups that interact with the suffix Food: hlaf, woter; and
Skills/knowledge. Our findings also prove that concrete nouns were not used as bases for the suffix, which can work mostly with abstract and non-countable nouns.

The semantic groups of derivatives coincide with the meaning of bases. Most cases are found in:

1) Abstraction - 14 cases;

$$
\begin{aligned}
& \text { e.g. N, f ár -leást- } \varnothing \text { (dishonour) } \\
& \mathrm{N}, \mathrm{f} \quad \text { ár(honour) - lack }
\end{aligned}
$$

FEM.NOM.SG.

2) Traits of Character - 7 cases;

$$
\begin{aligned}
& \text { e.g. } \mathrm{N} \text {, f réce -leást- } \varnothing \text { (carelessness) } \\
& \mathrm{V}, \mathrm{w} 1 \text { récan - lack FEM.NOM.SG. }
\end{aligned}
$$

Other semantic groups are Skills/knowledge and Physiological Activities.

A stative suffix -wíse in $\mathrm{OE}$ as majority of feminine forming suffixes tends to create nouns with abstract meaning. Despite a scarce number of nouns bearing this suffix, a tendency to indicate abstractions is obvious.

Bases the suffix is added to denote people, religion, result, lifeless objects, geographical names and military notions. The following tendency is revealed: concrete nouns (mostly of masculine gender 10 examples) work with -wíse to form abstract ones. The suffix is from Proto-Germanic *wison "appearance, form, manner".

The suffix -wīse forms nouns belonging to the following groups: Skills/knowledge, Result, Administration, Notions of Humans and Lifeless Objects.

Abstraction - 6 cases;

e.g. N, f riht -wīse $-\varnothing$ (justice)

Adj. riht - state FEM.NOM.SG.;

The suffix -ráeden is added to the bases denoting People (10 cases), Objects (3 cases) and Activities (6 cases) and forms derivatives of abstractions, result and social activity groups. Its meaning "state or condition" is predetermined by its etymology as -rǽden comes from a noun "rǣden" ("condition, state"), from Proto-Germanic *raidīniz ("arrangement, ordinance, authority"). Due to its semantic peculiarities the suffix form derivatives only from nouns (35) and adjectives (2).

As to the words formed with the suffix they belong to 12 different semantic groups, but only 4 groups are represented by a valid number of derivatives. Among those groups the most numerous one is result.

Result -7 cases;

$$
\begin{array}{cl}
\text { e.g. N, f cwid -rǽden } & -\varnothing \text { (agreement) } \\
\text { N, m cwild - state } & \text { FEM.NOM.SG.. }
\end{array}
$$

The next group is social activities formed on the bases of social stratifications (denoting functions of different roles) and social activities.

Social Activities - 7 nouns;

$$
\text { e.g. N, f ping -rǽden - Ø (advocacy) }
$$$$
\text { N,n ping -process - FEM.NOM.SG }
$$

Other two semantic groups (abstraction and traits of character) continue the overall tendency of the suffix towards anthropocentrism.

Abstraction - 6 cases;

$$
\begin{array}{cl}
\text { e.g. N, f teón } & \text {-rǽden }-\varnothing \text { (wrong) } \\
\text { N,m teón } & - \text { state FEM.NOM.SG. }
\end{array}
$$

The stative suffix -wist is from a combining form of Old English wist ("being"), akin to Old English verb wesan ("to be"). The semantic content of the suffix relates to existence in various forms abstract like "existence" 
itself, food to support it, result like "stability" and "protection", and structures to protect existence.

The peculiarity of the suffix in comparison to other feminine suffixes is that it more willingly works with simple prepositions of common Indo-European origin like OE samod - Indo-European *sm- (together). Other parts of speech that are used for coining new words are nouns and verbs.

The suffix coins nouns belonging to the following groups:

$$
\begin{aligned}
& \text { Result - } 4 \text { cases; } \\
& \text { e.g. N, f mund -wist }-\varnothing \text { (protection) } \\
& \mathrm{N} \text {, f mund - state FEM.NOM.SG. } \\
& \text { Abstract - } 2 \text { cases; } \\
& \text { e.g. N,f ed -wist }-\varnothing \text { (existence) } \\
& \text { Adj. ed - state FEM.NOM.SG.; } \\
& \text { Food - } 3 \text { cases; } \\
& \text { e.g. N, f dæg -wist - }-\varnothing \text { (daily food) } \\
& \text { N, m dæg - state FEM.NOM.SG.; }
\end{aligned}
$$

The suffix -pu forms abstract nouns from verbs (2 cases), adjectives (10 cases) and nouns ( 8 cases). It can be noted that the number of semantic groups is low in comparison with other suffixes ( 7 groups only) and nouns denoting abstraction, feelings and character prevail in the data in question.
Feelings - 4 cases;

$$
\begin{array}{ccc}
\text { e.g. N, f wrǽp } & - \text { pu } & -\varnothing \text { (anger) } \\
\text { N, f wrǽp } & - \text { abstraction } & \text { FEM.NOM.SG.; }
\end{array}
$$

Abstract -8 cases;

e.g. N, f earm -pu $-\varnothing$ (misery)

Adj earm - abstraction FEM.NOM.SG..

The etymology of suffix "-stów determines the meaning of location in its derivatives. It is from stōw ("place"), from Proto-Germanic *stōwō ("place"), from Proto-Indo-European *stehw- ("to set, place"). Thus, the semantic groups that are characteristic of the suffix are Structures, Locations, War, Religion.

Structures - 9 cases;

$$
\begin{aligned}
& \text { e.g. N, f wíc -stów - - (dwelling) } \\
& \text { N,n wíc - location FEM.NOM.SG.; } \\
& \text { Locations - } 18 \text { cases; } \\
& \text { e.g. N, f hege -stów } \quad-\varnothing \text { (hedged place) } \\
& \mathrm{N} \text {, m hege - location FEM.NOM.SG. }
\end{aligned}
$$

The overall analysis of feminine derivatives in the Old English period shows certain tendencies, which are easy to be shown on Chart 1, which is the visual representation of the number of suffixes and semantic components they bring into play in the derived feminine nouns (from 1 to 21).

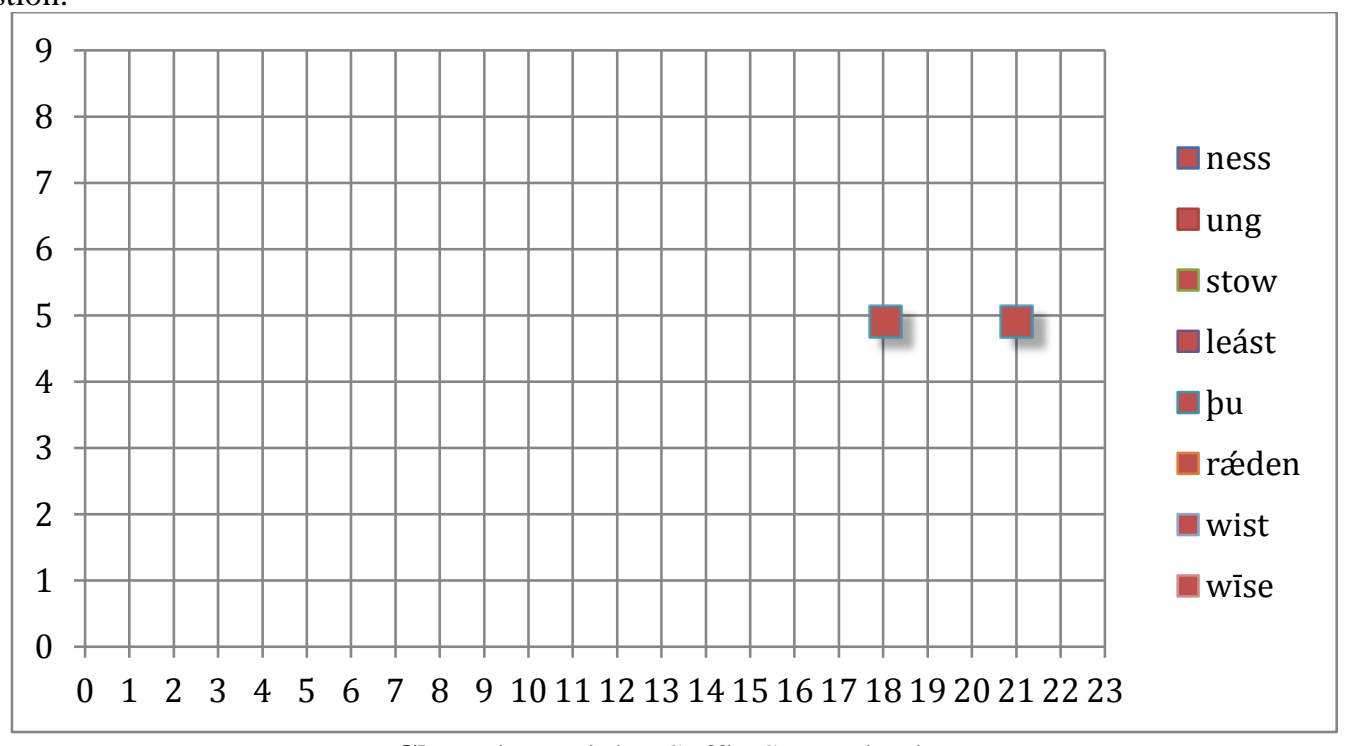

Chart 1. Feminine Suffix Semantization

Thus, within the scope of our analysis we may define the following semantic segments of feminine derivatives as primary: Traits of Character, Feelings, Abstractions, Result of Actions. Secondary segments are Social Activities, Physical Activities, Structures.

It definitely proves the fact that feminine derivatives in Old English show a certain tendency towards abstraction and anthropocentrism, almost ignoring semantic components connected with Administration, Social Stratification, and Lifeless Objects etc.

Simultaneous analysis of bases the feminine suffixes work with in the Old English period shows the following:

- $\quad$ the most frequent semantic group among bases is Activities (Social, Physical and Physiological) due to the productivity of suffixes -ness and -ung;

- $\quad$ the next group represents Abstractions (feelings and traits of character);

e.g. N,f ge- gearw

-ung

$-n e s s$
Lifeless Objects are also used to coin feminine nouns in Old English;

denoting Result.

suffixes under analysis work well with nouns

As we can see the formation of abstraction segment in the Old English contradicts to the statement of R. Lieber that affixes do not add semantic content that is already available within a base word (simplex or derived) [3, p. 161]. This statement is in turn based on I. Plag's work where he suggests another semantic restriction on affixation, this time a somewhat more general one: we should not expect to find suffixes that form abstract nouns which attach to other suffixes which form abstract nouns [5, p. 76]. This Old English deviation from the general rule requires a detailed research. Our brief analysis of Old English suffixes suggests that redundancy in derivation is possible for base + suffix and for base+suffix+suffix: - Ø (preparation) 
RESULT- N, n gearwe (clothing) - ABSTRACT- ABSTRACT FEM.NOM.SG.

Conclusion. The analysis of Old English derivation has yielded a number of significant results. First, in the Old English period the most productive gender in terms of word-formation was feminine. All analysed derivatives were coined from nouns of all three genders, adjectives, verbs, adverbs, and other parts of speech.

Secondly, we can state that each suffix though having a number of semantic components realized has a certain focal meaning. This focal meaning has sometimes additional aspects and depends upon the feminine gender suffixes peculiarities and etymology of the suffix. It means that not all of domains of usage could be distinguished as primary. The results indicate that majority of suffixes would reveal $3-5$ semantic segments, while a limited amount of suffixes bring about $7-9$ segments.
Semantic components characteristic for certain sets of suffixes in the Old English period are analysed, with Abstractions being the leader in terms of its coinage productivity. No less important are Feelings and Traits of Character. Result of Actions as well as secondary semantic components like Social Activities and Physical Activities; they reveal the recurrent use of verbal bases for feminine suffixes.

The bases used to coin feminine nouns denoted Activities, Abstractions, Lifeless Objects and Results of Actions.

We define the study of semantic peculiarities of masculine and neuter derivatives as the further steps of our research, as the complex analysis would provide a broad outlook on the issue of derivational semantics.

\section{REFERENCES}

1. Bosworth, J. and T. N. Toller. 1973 (1898). An Anglo-Saxon Dictionary. Oxford: Oxford University Press.

2. Kastovsky, Dieter. 2006. Typological changes in derivational morphology. In Ans Van Kemenade \& Bettelou Los (eds.), The handbook of the history of English, pp. 151-177. Oxford: Blackwell.

3. Lieber, Rochelle. 2004. Morphology and lexical semantics. Cambridge ; New York : Cambridge University Press.

4. Mel'čuk, Igor. 2006. Aspects of the theory of morphology. I by Igor Mel'čuk; edited by David Beck. Berlin: Mouton de Gruyter.

5. Plag, Ingo. 1999. Morphological productivity: structural constraints in English derivation (Topics in English Linguistics, 28). Berlin and New York: Mouton de Gruyter.

6. Pounder, Amanda. 2000. Processes and paradigms in wordformation morphology. Berlin: Mouton de Gruyter.

7. Zbierska-Sawala, Anna. 1992. Semantic Aspects of Derivational Affixation in the AB Language.Frankfurt/Mainz: Peter Lang. 